\title{
PRÁTICAS EDUCATIVAS EM MUSEUS DA EDUCAÇÃO: ALGUMAS EXPERIÊNCIAS
}

\author{
Christine Müller \\ CIVILIS/FE/UNICAMP \\ cmchrismuller50@gmail.com
}

\section{RESUMO}

Este trabalho faz parte da tese de doutorado defendida pela autora em junho de 2019. Aborda práticas educativas em museus da educação e pedagógicos, com foco nas interações que ocorrem no espaço do museu. Dentro deste enfoque foi formulado o seguinte problema: as propostas interativas das exposições museológicas têm realmente permitido o diálogo com as experiências do público? Segundo Wagensberg (2006), há três formas de promover a interatividade nas exposições. São elas a interatividade manual" (hands on), a interatividade mental (minds on) e a a interatividade cultural (heart on). A pesquisa que se articula ao projeto "Preservação do Patrimônio Histórico Educativo", sob a coordenação da Profa. Dra. Maria Cristina Menezes tem como objetivo apresentar e discutir algumas práticas educativas que estão sendo desenvolvidas no Memorial laboratório de estudos e pesquisas escolares da E.E. Carlos Gomes - Campinas-SP. Uma das escolas em que o projeto mencionado desenvolve pesquisas. Para essa investigação foram empregadas as pesquisas relacionadas à educação em museus articuladas a um referencial metodológico no qual se busca, na bibliografia sobre museologia crítica e educação patrimonial. Com o objetivo de justificar a metodologia que norteou o presente trabalho foi implementada uma proposta/vivência, junto às 3 turmas de $6^{\circ}$ ano, da Escola Estadual Carlos Gomes, Campinas-SP, denominada Sensibilização e Visita ao Memorial da Escola Estadual Carlos Gomes.

Palavras-chave: Educação em museus. Educação patrimonial. Museus da educação.

\section{PRÁCTICAS EDUCATIVAS EN MUSEOS EDUCATIVOS: ALGUNAS EXPERIENCIAS}

\section{RESUMEN}

Este trabajo forma parte de la tesis doctoral defendida por el autor en junio de 2019. Aborda las prácticas educativas en museos educativos y pedagógicos, enfocándose en las interacciones que ocurren en el espacio del museo. Dentro de este enfoque, se planteó el siguiente problema: las propuestas interactivas de las exposiciones en museos realmente permitieron el diálogo con las experiências del público? Según Wagensberg (2006), hay tres formas de promover la interactividad en las exposiciones. Son interactividad manual (práctica), interactividad mental (mente activa) e interactividad cultural (corazón activo). La investigación vinculada al proyecto "Preservación del patrimonio histórico educativo", bajo la coordinación de Profa. La Dra. Maria Cristina Menezes tiene como objetivo presentar y discutir algunas prácticas educativas que se están desarrollando en el laboratório de estudios y investigación escolar de E.E. Carlos Gomes-Campinas-SP. Una de las escuelas donde el proyecto mencionado desarrolla investigación. Para esta investigación, se utilizaron investigaciones relacionadas con la educación en museos, vinculadas a un marco 


\title{
(cc) $\mathrm{BY}$
}

metodológico en el que se busca la bibliografia sobre museología crítica y educación patrimonial. Para justificar la metodologia que guió el presente trabajo, se implementó una propuesta/experiencia, junto con las 3 clases de 6to año, de la Escuela Estatal Carlos Gomes, Campinas-SP, llamada "Sensibilización y Visita al Memorial de la Escuela Estatal Carlos Gomes".

Palabras clave: Educación museística. Educación patrimonial. Museos de educación.

\section{EDUCATIONAL PRACTICES IN EDUCATIONAL MUSEUMS: SOME EXPERIENCES}

\begin{abstract}
This work is part of the doctoral thesis defended by the author in June 2019. It addresses educational practices in educational and pedagogical museums, focusing on the interactions that occur in the museum space.Within this approach, the following problem has been formulated: have the interactive proposals of museum exhibitions really allowed dialogue with the experiences of the public? According to Wagensberg (2006), there are three ways to promote interactivity in exhibitions. They are manual interactivity (hands on), mental interactivity (minds on) and cultural interactivity (heart on). The research that is related to the project " Preservation of the Historical Educational Heritage", coordinated by Profa. Dr. Maria Cristina Menezes aims to presente and discuss some educational practices that are being developed in the Memorial Laboratory of studies and school research of E.E. Carlos Gomes-Campinas-SP. One of the schools in which the mentioned project develops research. For this investigation were utilized researches related to education in museums connected to a methodological framework, in which search is conducted about the literature on critical museology and heritage education. Finally, with the objective of justifying the methodology that guided this work, a proposal was submitted to the class of 6 grade students of the "Escola Estadual Carlos Gomes, Campinas - SP, called "Awareness and Visit to the Escola Estadual Carlos Gomes Memorial".
\end{abstract}

Keywords: Museum education. Heritage education. Education museums.

\section{PRATIQUES EDUCATIVES DANS LES MUSEES EDUCATIFS: QUELQUES EXPERIENCES}

\section{RESUME}

Ce travail fait partie de la thèse de doctorat défendue par l'auteur en juin 2019. Aborde les pratiques éducatives dans les musées de l'éducation et pédagogique, en mettant l'accent sur les interactions qui ont lieu dans l'espace du musée. Dans cette optique, le problème suivant a été formulé : les propositions interactives des expositions muséologiques ont-elles réellement permis le dialogue avec les expériences du public? Selon Wagensberg (2006), il existe trois façons de promouvoir l'interactivité dans les expositions. Ce sont elles l'interactivité manuelle" (hands on), l'interactivité mentale (minds on) et l'interactivité culturelle (heart on). La recherche qui s'articule avec le projet "Préservation du Patrimoine Historique Éducatif", sous la coordination de la Profa. Dra. Maria Cristina Menezes a pour objectif de présenter et de discuter certaines pratiques

Rev. Iberoam. Patrim. Histórico-Educativo, Campinas (SP), v. 6, p. 1-23, e020010, 2020. 


\section{$(\mathrm{cc})$ EY}

éducatives en cours de développement au Memorial laboratoire d'études et de recherches scolaires de E.E. Carlos Gomes - Campinas-SP. Une des écoles dans lesquelles le projet mentionné développe des recherches. Pour cette recherche ont été employées les recherches liées à l'éducation dans les musées articulées vers un référentiel méthodologique dans lequel on cherche, dans la bibliographie sur la muséologie critique et l'éducation patrimoniale. Afin de justifier la méthodologie qui a guidé ce travail, une proposition/expérience a été mise en œuvre, à côté des 3 classes de sixième année, de l'École d'Etat Carlos Gomes, Campinas-SP, appelée "Sensibilisation et Visite au Mémorial de l'École d'Etat Carlos Gomes".

Mots-clé: L'éducation dans les musées. L'éducation patrimoniale. Les musées de l'éducation.

\section{INTRODUÇÃO}

O Conselho Internacional de Museus-ICOM, define como Museu, toda instituição permanente, sem fins lucrativos, aberta ao público, que adquire, conserva, pesquisa e expõe coleções de objetos de caráter cultural ou científico para fins de estudo, educação e entretenimento.

A definição de Museu segundo o Ministério de Cultura - IPHAN/MinC é mais específica: “O museu, para os efeitos de lei, é uma instituição com personalidade jurídica, com ou sem fins lucrativos, ou vinculada a outra instituição com personalidade jurídica própria, aberta ao público, a serviço da sociedade e de seu desenvolvimento e que apresenta as seguintes características:

I - o trabalho permanente com o patrimônio cultural, incluindo nessa designação o natural, tangível, intangível, digital, genético e paisagístico;

II - a presença de acervos e exposições colocados ao serviço da sociedade com o objetivo de propiciar a ampliação do campo de possibilidades de construção identitária, a percepção crítica da realidade, a produção de conhecimentos e oportunidades

III - o desenvolvimento de programas, projetos e ações que utilizem o patrimônio cultural como recurso educacional, turístico e de inclusão social;

IV - a vocação para a comunicação, a exposição, a documentação, a investigação, a interpretação e a preservação de manifestações e bens culturais e naturais;

V - a democratização do acesso, uso e produção de bens culturais de modo a contribuir para a promoção da dignidade da pessoa humana;

VI - a constituição de espaços de relação e mediação cultural com orientações políticas, culturais e científicas diferenciadas entre si. 


\section{$(\mathrm{cc})$ EY}

Dessa forma, para fins deste estudo, optou-se pela definição do IPHAN, tal como o espaço foi denominado no âmbito do Projeto "Preservação do Patrimônio Histórico Educativo", desenvolvido pelo CIVILIS/FE/UNICAMP. Assim nomeou-se de Memorial Laboratório de Estudos e Pesquisas Escolares da Escola Estadual "Carlos Gomes” - Campinas-SP.

O Memorial insere-se, também, na definição de um museu de educação, pois é um espaço destinado para a discussão sobre história da educação por meio dos objetos e dos documentos escolares que ali se encontram.

Conforme Álvarez Domínguez (2016), um Museu de Educação, mais que um mero espaço de informação e comunicação, deve ser concebido como um centro de interpretação com o objetivo de valorizar o patrimônio etnográfico da educação. Deve ser compreendido como um lugar de memória educativa, que seja capaz de integrar como objetivos fundamentais, a tutela, conservação, difusão e interpretação dos objetos, ideias e valores pedagógicos de uma sociedade. São considerados locais de conhecimento e recordação na medida em que são capazes de agregar valor à memória da educação e da escola. Os objetos visíveis e materiais da memória patrimonial histórico educativa apresentam-se como um bom trampolim de estudo, se formos capazes de entender e construir significados que vão mais além do meramente coloquial e evidente.

O Projeto do grupo CIVILIS "Preservação do Patrimônio Histórico Educativo: Acervos Escolares de Campinas", coordenado pela profa. Dra. Maria Cristina Menezes, da Faculdade de Educação da Universidade Estadual de Campinas, FE/UNICAMP/Brasil, tem como objetivo a preservação e a organização do acervo, além da estruturação de exposições de cunho interativo.

Para a pesquisa em questão, considerou-se a exposição interativa a partir do esquema estruturado por Wagensberg (2006). Segundo o autor há três formas de promover a interatividade nas exposições. Uma das formas de interação consiste na "interatividade manual” (hands on), muito empregada em museus de ciência, é aquela em que o visitante tem uma interação mecânica com um objeto e assim é demonstrado um fenômeno. A segunda forma traduz-se em uma interatividade mental (minds on), ou seja, os elementos de interação estimulam o funcionamento da mente, instigando os visitantes a empreender um "exercício" mental, formulando questões, solucionando problemas, criando analogias e percebendo contradições. Tal interatividade não depende do intermédio de recursos digitais, podendo a experiência ser "desencadeada" em momentos de interação entre visitantes, por um processo de mediação ou visita guiada. Finalmente, a interatividade cultural (heart on), que cria conexões e identidade entre a exposição ou objeto 


\section{$(\mathrm{cc})$ EY}

museal, o visitante e a sociedade em que se insere. Relaciona-se às questões emocionais de vivenciar uma experiência.

O Memorial representa uma rica oportunidade para que tanto os estudantes quanto os professores da escola tenham a possibilidade de conhecer sobre a história da escola com o suporte da história da educação e da comunidade de inserção.

\section{PROPOSTA DE SENSIBILIZAÇÃO E VISITA AO MEMORIAL LABORATÓRIO DE ESTUDOS E PESQUISAS ESCOLARES}

Em 22 de novembro de 2017 foi realizada uma proposta/vivência junto a três turmas de $6^{\circ}$ ano denominada "Sensibilização e Visita ao Memorial da Escola Estadual 'Carlos Gomes". Tal proposta foi coordenada pela professora Dra. Maria Cristina Menezes e contou com a então equipe de apoio do projeto, alunos bolsistas trabalho SAE/UNICAMP, alunos do Ensino Médio, bolsistas do PIBIC-EM, três pós-graduandas do CIVILIS, contando ainda com o apoio da instituição escolar.

A proposta/vivência incluiu um trabalho prévio com duas professoras do Ensino Fundamental, que em sala de aula anteciparam a discussão com os respectivos alunos.

FIGURA 1- Alunos no Salão Nobre da E.E. Carlos Gomes: discussão prévia sobre a questão da memória

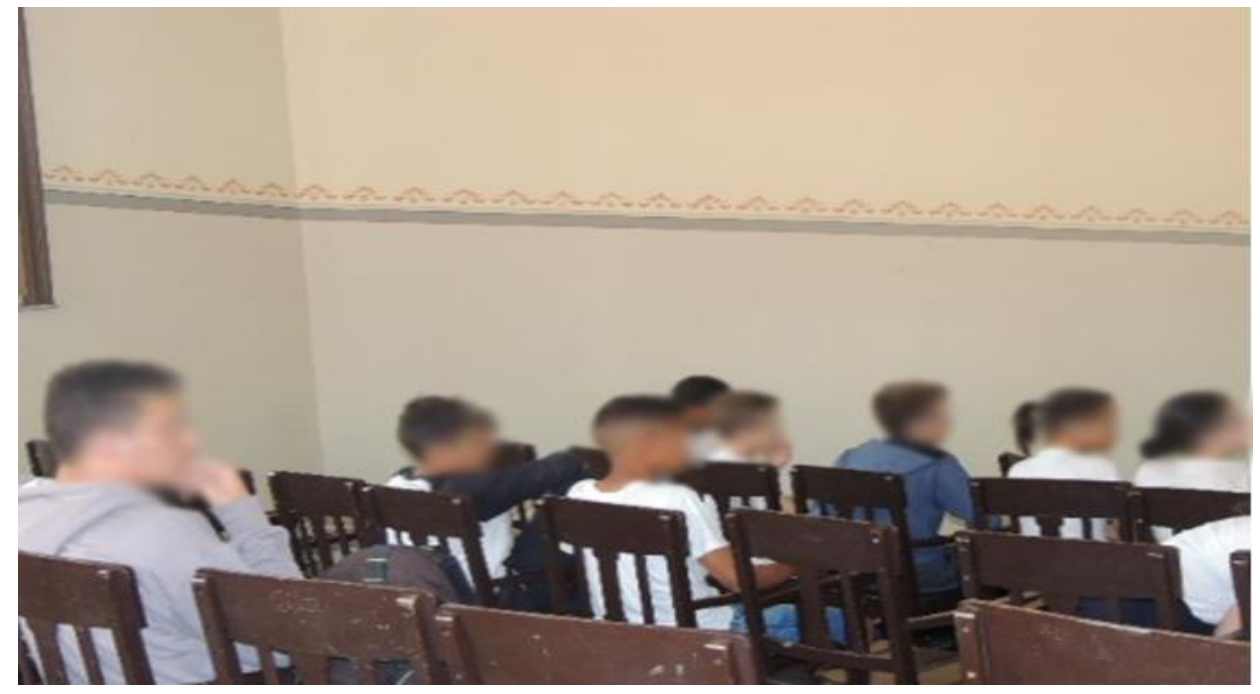

Fonte: Acervo Grupo CIVILIS - FE-UNICAMP 


\section{$(\infty)$ EY}

FIGURA 2 - Imagem do Power Point apresentado no Salão Nobre da EE Carlos Gomes, para os alunos do $6^{\circ}$ ano, seguido de discussão, 2017

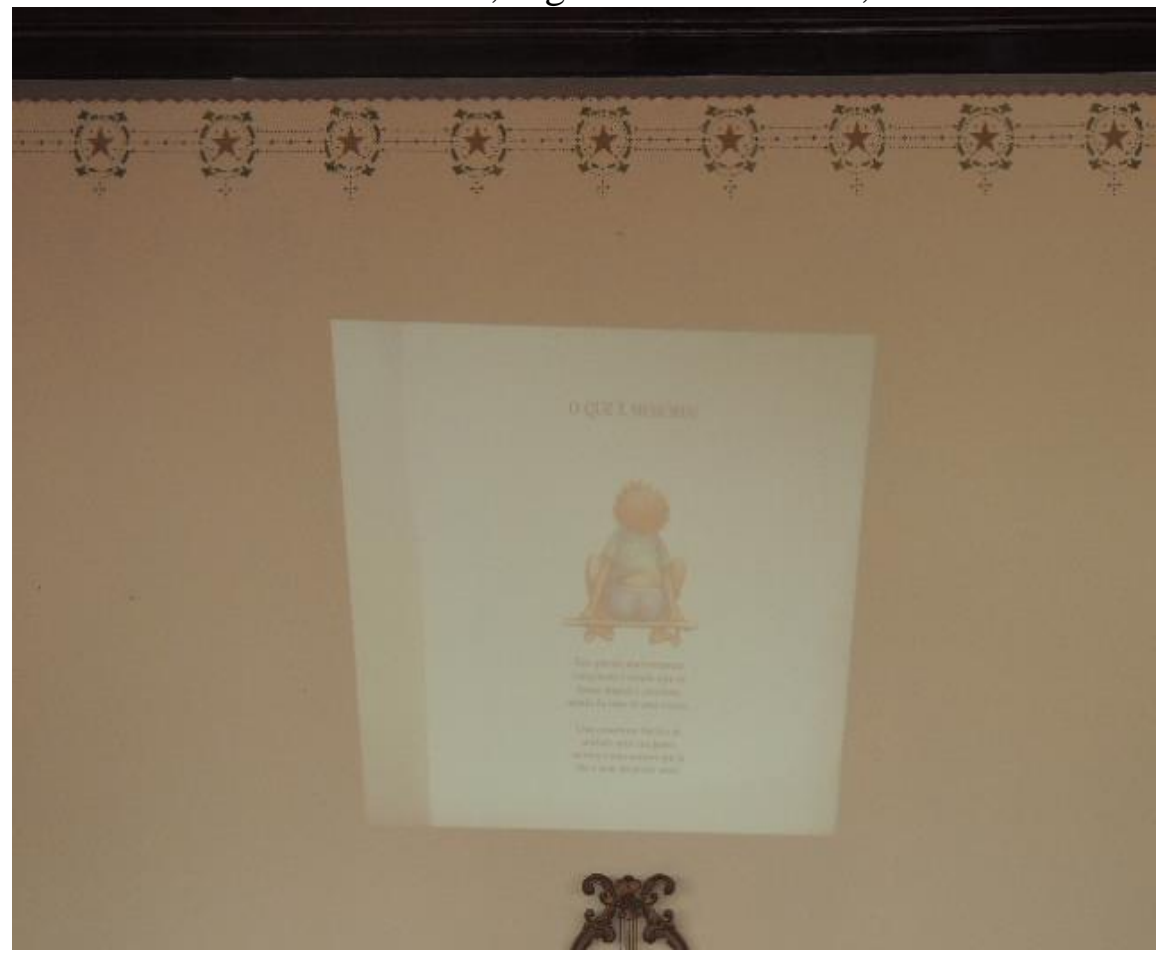

Fonte: Acervo Grupo CIVILIS - FE-Unicamp

A discussão do conceito de memória a partir da apresentação em power point e discussão do livro "Guilherme Augusto Araújo Fernandes" (FOX, 2002, em que é abordada a questão da perda da memória entre idosos) com os alunos e professores no salão nobre da Escola.

Na obra Memória e Sociedade: lembranças de velhos (1994), Bosi discute as zonas limite entre história e memória, articuladoras da vivência. As vozes que atuam na recuperação da memória demonstram a interferência de vários fatores no momento do relato. Um deles relaciona-se à relatividade da memória, que envolve não apenas lembranças, mas também silêncios e esquecimentos. Existe uma ligação entre memória, lembranças e esquecimento. Lembrança e esquecimento constituem uma unidade entre complementares e opostos. Constatou-se que dentre as possibilidades de abordar a memória, a partir da leitura do livro de Fox (2002) relacionava-se à perspectiva da autora.

O salão nobre também foi o local em que os alunos apresentariam as suas "caixinhas de memória", antes da vivência no museu. A atividade das "caixinhas" decorreu do projeto do Professor Pablo Álvarez Dominguez, da Universidade de Sevilha, então na FE/UNICAMP, no primeiro semestre de 2017, como professor convidado do CIVILIS/FE/UNICAMP. Na ocasião, o 


\section{$(\infty))_{\text {EY }}$}

Professor Dominguez em minicurso oferecido pelo CIVILIS, no PPG/FE/UNICAMP, realizou uma dinâmica articulada ao projeto, que então desenvolvia no Museu Pedagógico, da Universidade de Sevilha, denominado "Maletas Pedagógicas". Almejava-se, após a dinâmica com as "caixinha de memória", a visita à exposição interativa para se vivenciar o espaço museu.

FIGURA 3 - Alunos do $6^{\circ}$ ano no Salão Nobre da E.E. Carlos Gomes: em apresentação das "caixinhas de memórias" deles, 22 de novembro de 2017

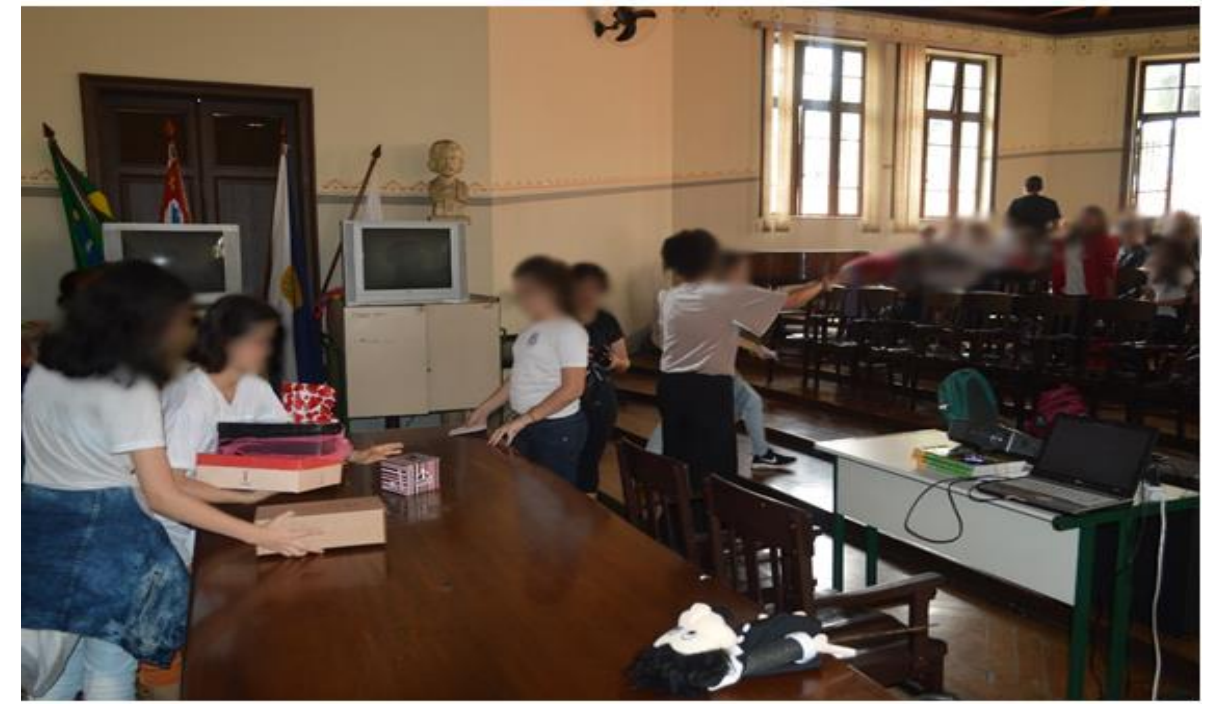

Fonte: Acervo Grupo CIVILIS - FE-Unicamp

Uma semana antes de os alunos visitarem a exposição, foi solicitado, pelos professores, que eles trouxessem sua "maleta pedagógica" de casa. Tal maleta poderia ser uma caixa ou a maleta da mãe ou da avó. O importante aqui é a simbologia, relacionada a possibilidade de viajar, uma viagem pedagógica. Dessa forma, foi pedido que trouxessem dentro da maleta objetos da sua vida escolar e/ou de sua família (boletins, cartilhas, fotos, entre outros objetos). Dessa forma, no dia marcado para a visita à exposição, teriam, primeiramente, um momento para contarem suas histórias por meio dos objetos pessoais.

Conforme Álvarez Domínguez (2013) o uso de maletas pedagógicas como recurso de ensino e aprendizagem encontra-se articulado à aplicação de uma particular metodologia didática que busca a renovação pedagógica. A maleta pedagógica é baseada em quatro elementos fundamentais: 1) Uma mala 2) Um caderno 3) reflexões histórico-educativas e 4) Objetos e/ou materiais pedagógicos. Representam para o pesquisador que, através de uma viagem pedagógica, seja possibilitado aos estudantes de pedagogia, da Universidade de Sevilha, analisar e projetar 


\section{$(\mathrm{cc})$ EY}

diferentes apresentações histórico-educativas; em que possam redefinir conceitos, conhecer e identificar novas realidades; adquirir competências básicas.

A metodologia, das maletas pedagógicas, é considerada um novo recurso didático para o aprendizado da história da educação na universidade.

Los estudiantes de la Universidad actual necesitan encontrar relaciones entre lo que aprenden y el mundo global que les rodea; entre lo que se preguntan y lo que se les responde; entre lo que quieren conseguir y lo que se les aporta para ello; entre lo que se les cuenta que hay que hacer y lo que al mismo tiempo no hacemos; entre lo que ellos esperan y lo que nosotros podemos aportarles. La renovación pedagógica en sí misma, además de pretender la mejora del aprendizaje del alumnado, se presenta como una posibilidad que tiene el profesorado para encontrarse consigo mismo en la enseñanza, pues ésta ha de llevarle a investigar sobre nuevas formas de comunicación; nuevas pautas y mecanismos para hacer pensar al alumnado; nuevos recursos para que el alumnado pueda aprender significativamente; etc. (ÁLVAREZ DOMÍNGUEZ, 2013, p. 2).

Objetiva-se que o material a ser ensinado seja estimulante. Além do emprego de métodos de ensino e de tarefas acadêmicas que exijam dos estudantes envolverem-se ativamente no aprendizado.

Conforme o autor, são grandes as contribuições do uso das maletas pedagógicas como recurso didático inovador na universidade. Dessa forma, considera-se que tal metodologia possa ser utilizada como uma prática educativa em museus da educação.

\section{O dia da sensibilização e da visita à exposição "Siga Carlinhos, o Mascote do Memorial e conheça a exposição sobre a E.E. 'Carlos Gomes"' (Memorial da E.E. “Carlos Gomes" - 22 de novembro de 2017)}

A atividade/vivência iniciou-se no anfiteatro da escola com as 3 turmas de $6^{\circ}$ ano presentes. Primeiramente, ocorreu a apresentação de "Carlos Gomes", por meio do Carlinhos, o fantoche que representa o maestro campineiro que dá o nome à escola e que se tornou o patrono da escola, o qual mediou todo o processo, como "mascote" do memorial escolar. 


\section{$(\mathrm{cc}) \mathbf{E Y}$}

FIGURA 4 - Fantoche Carlinhos, o mascote do memorial

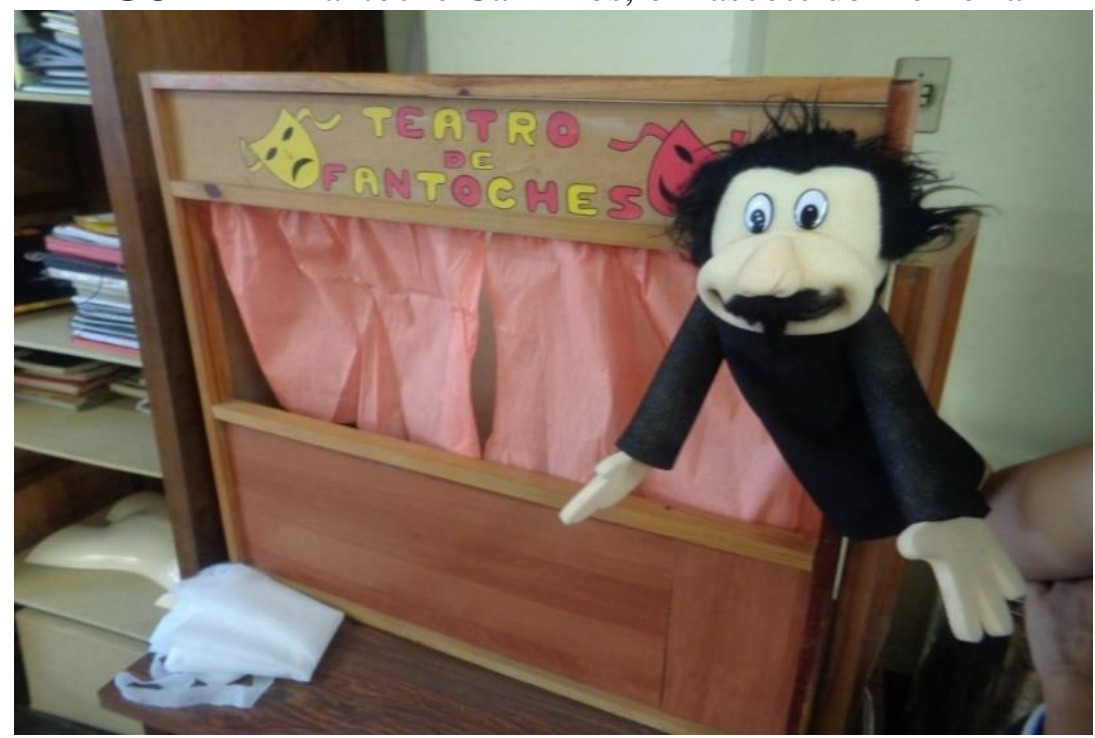

Fonte: Acervo Grupo CIVILIS - FE-Unicamp.

Em seguida, conduzidos pelo "Carlinhos, o mascote do memorial", os alunos foram estimulados a pensar sobre a história da escola por meio de imagens da mesma, acompanhadas de perguntas como: "Que lugar é este?"; "Vocês reconhecem este lugar?", “Onde está esta pintura?"; "De quem é este busto?", "Onde ele está?" "O que você conhece sobre a história da sua escola?" "Quem foi Carlos Gomes? Qual a importância dele?"

1) Que lugar é este?

FIGURA 5 - Piso da E. E Carlos Gomes - 2017

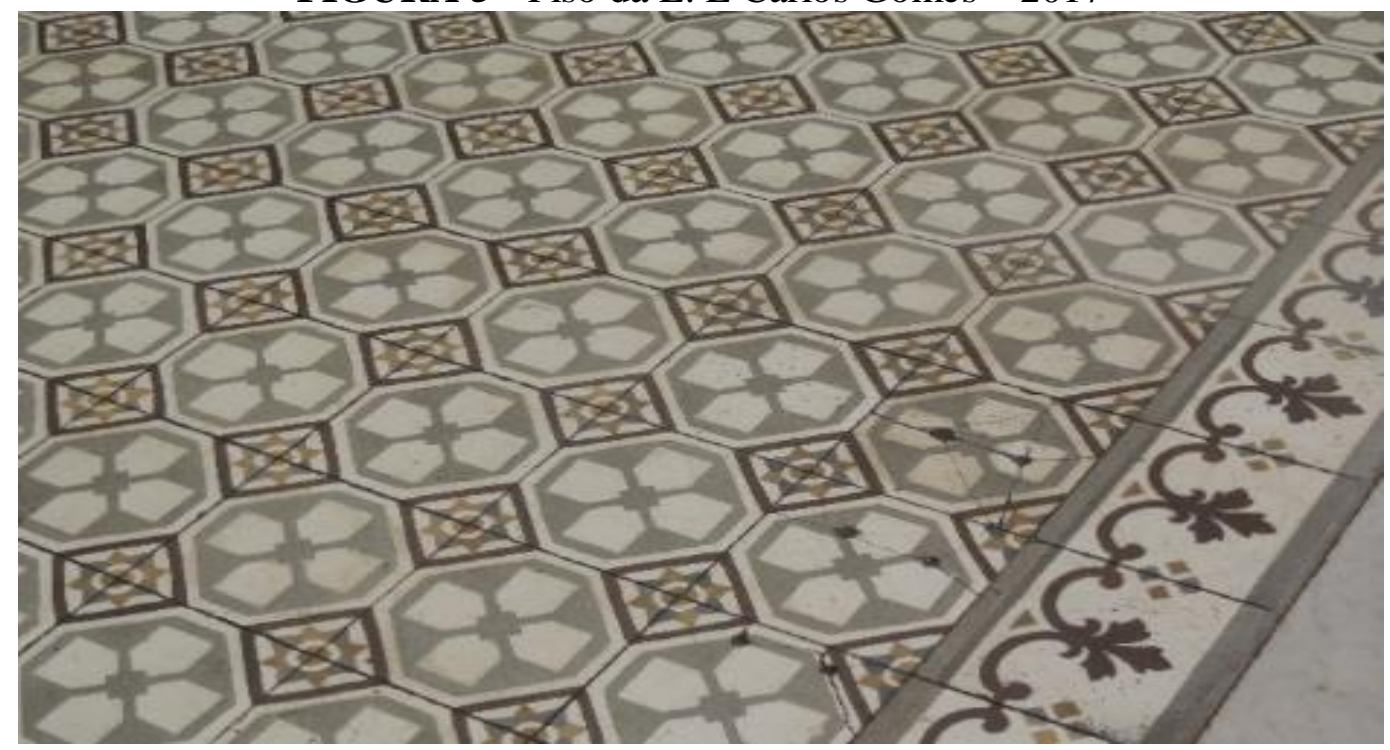

Fonte: Acervo Grupo CIVILIS - FE-Unicamp 


\section{$(\mathrm{cc}) \mathrm{EY}$}

2) Vocês conhecem este lugar?

FIGURA 6 - Teto da E.E. Carlos Gomes - 2017

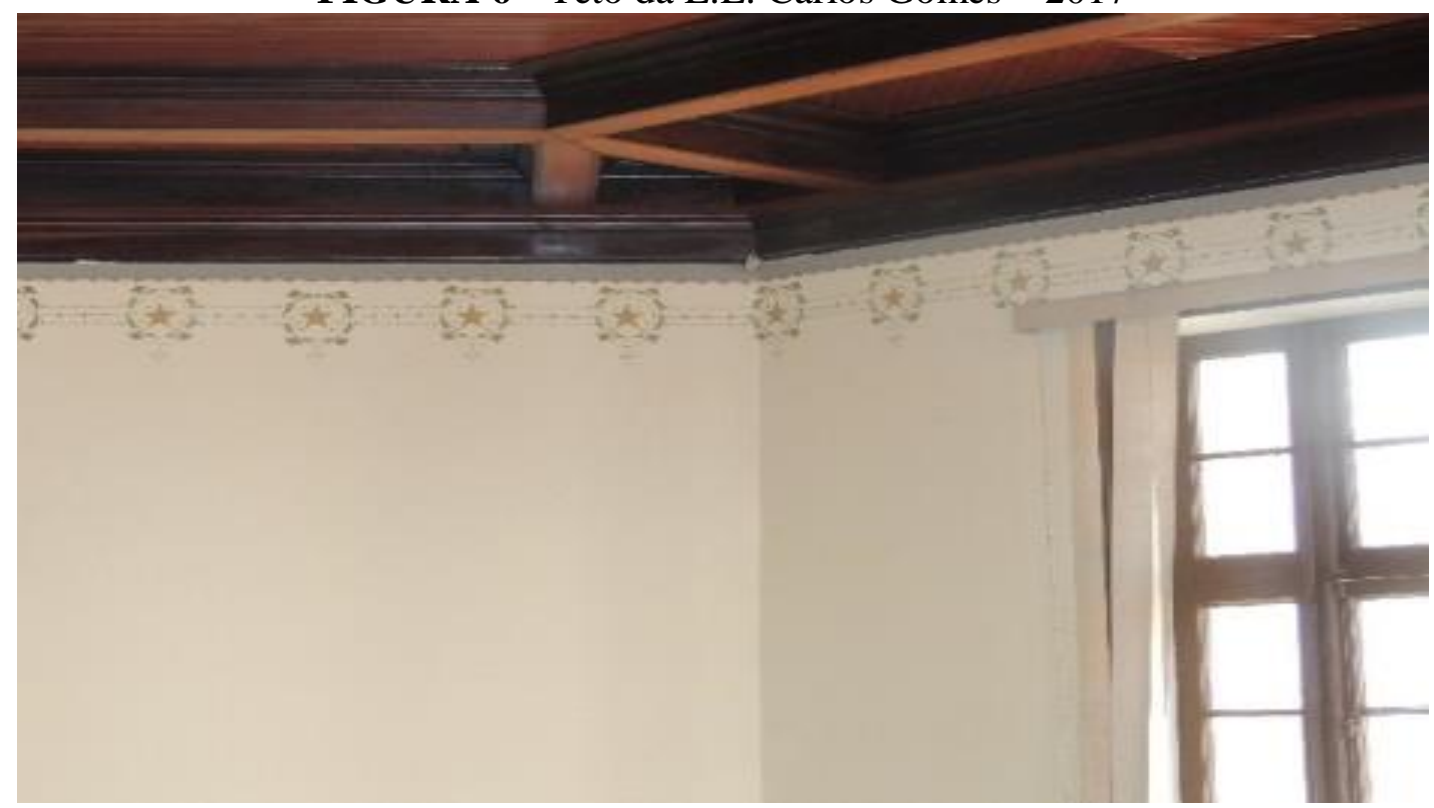

Fonte: Acervo Grupo CIVILIS - FE-Unicamp

3) De quem é este busto? Onde ele está?

FIGURA 7 - Busto de Carlos Gomes

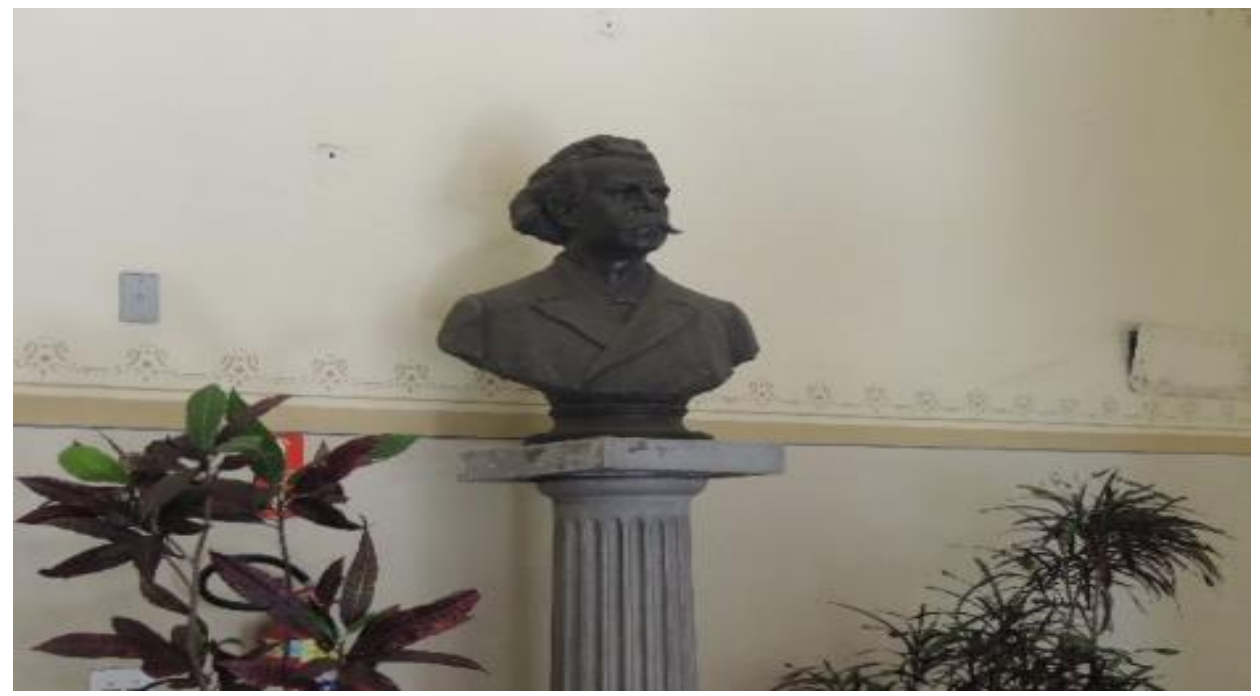

Fonte: Acervo Grupo CIVILIS - FE-Unicamp

Posteriormente, os alunos foram convidados a apresentarem os objetos escolares que haviam trazido nas "caixinhas", uma analogia às "maletas pedagógicas" descritas anteriormente. 


\section{(c)) BY}

FIGURA 8 - Alunos do $6^{\circ}$ ano no Salão Nobre - apresentação das “caixinhas pedagógicas" - 22 de novembro de 2017

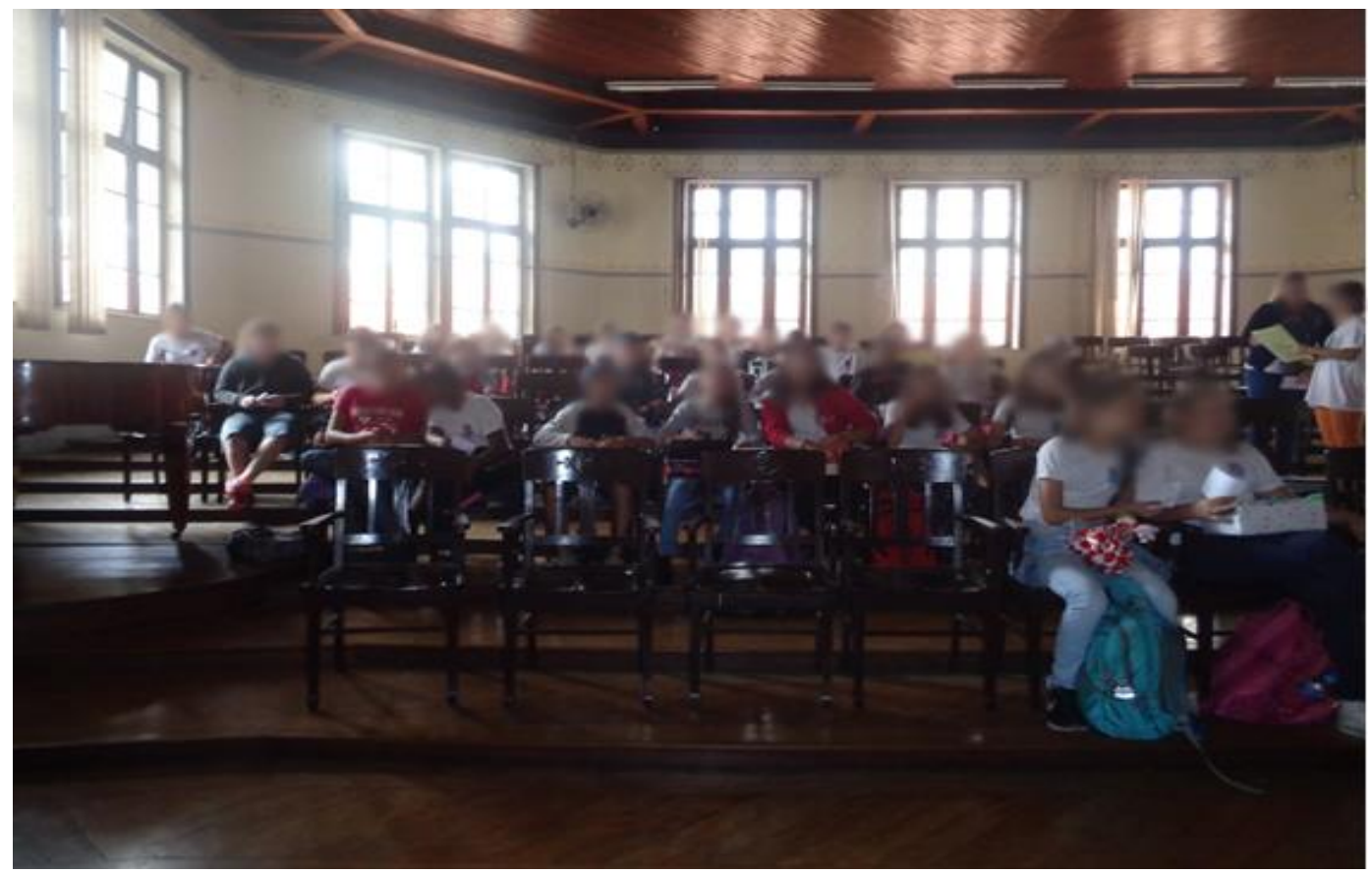

Fonte: Acervo CIVILIS - FE-Unicamp

As caixinhas tinham sido solicitadas, antecipadamente, em sala de aula, pelas professoras dos $6^{\circ}$ anos que se dispuseram a participar, com o objetivo de ser discutido o conceito de memória.

Após explicarem sobre os objetos que haviam trazido nas "caixinhas" e que remetiam ao conceito de memória, os alunos, antes de visitarem a exposição, foram incentivados a refletirem sobre a mesma e sobre o novo local em que precisou ser organizada. As memórias individuais relacionavam-se tanto às experiências escolares próprias quanto a de seus familiares. Em momento posterior, ao visitarem a exposição, poderiam realizar articulações.

Assim, nesse momento inicia-se o processo educativo desde o patrimônio mais individual do aluno (suas recordações, memórias) para chegar àquele patrimônio mais universal, coincidindo neste trânsito com as abordagens da história, da identidade, diversidade, alteridade.

De acordo com Michel Pollak existe uma relação muito estreita entre memória e sentimento de identidade, formando o sentido da imagem de si que a pessoa constrói e apresenta aos outros e a si mesma. "A memória é um elemento constituinte do sentimento de identidade, tanto individual como coletiva", e essa identidade individual é construída socialmente, ou seja, está essencialmente vinculada ao outro, é o processo de alteridade (POLLAK, 1992). 


\section{(cc) EY}

FIGURA 09 - Alunos do $6^{\circ}$ ano no Salão Nobre - apresentação das "caixinhas pedagógicas" - 22 de novembro de 2017

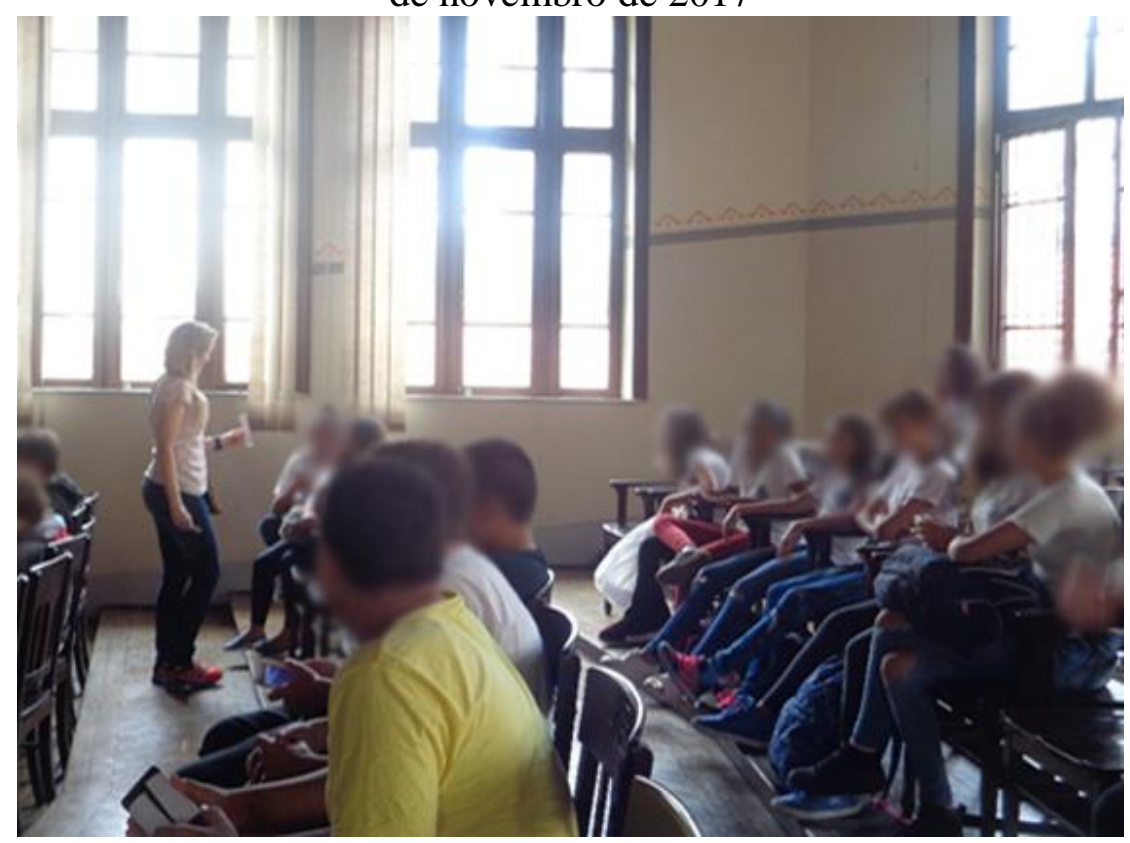

Fonte: Acervo CIVILIS - FE-UNICAMP

FIGURA 10 - alunos do $6^{\circ}$ ano no Salão Nobre - apresentação das caixinhas pedagógicas" - 22 de novembro de 2017

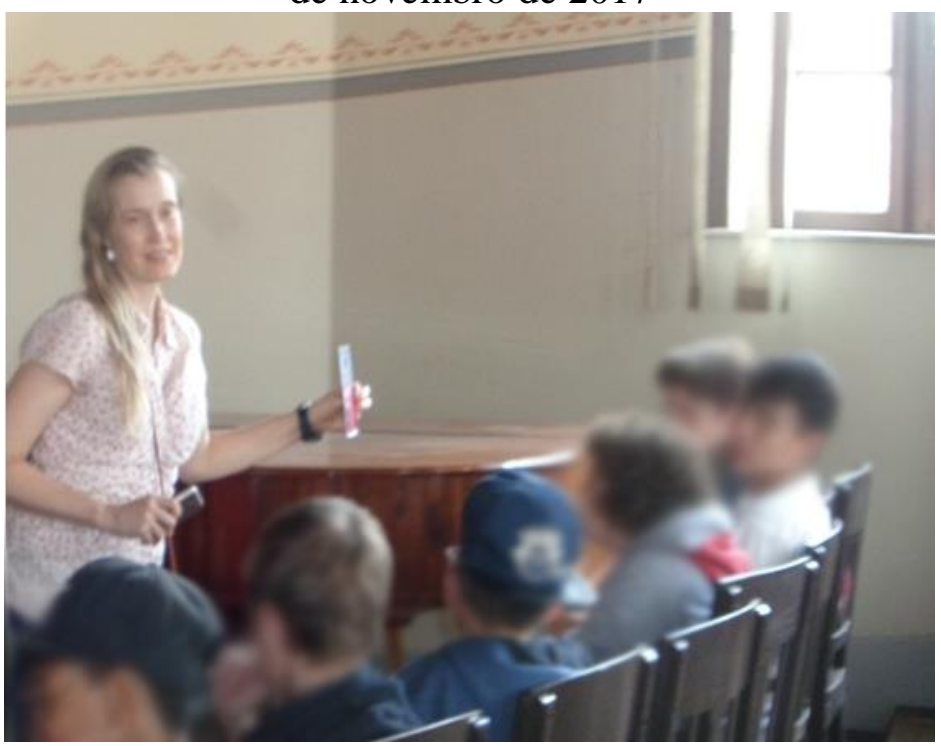

Fonte: Acervo CIVILIS - FE-Unicamp

A exposição precisou ser mudada para o porão, pois a escola recebeu um financiamento com o objetivo de algumas reformas internas, o que incluiu o espaço de exposição do Memorial. 


\section{(c) $\mathbf{E Y}$}

A notificação para a mudança ocorreu de forma repentina, mas não impossibilitou que a "proposta de sensibilização" ocorresse em local temporário.

FIGURA 11- Exposição em seu local permanente, antes da última reforma (outubro de 2017)

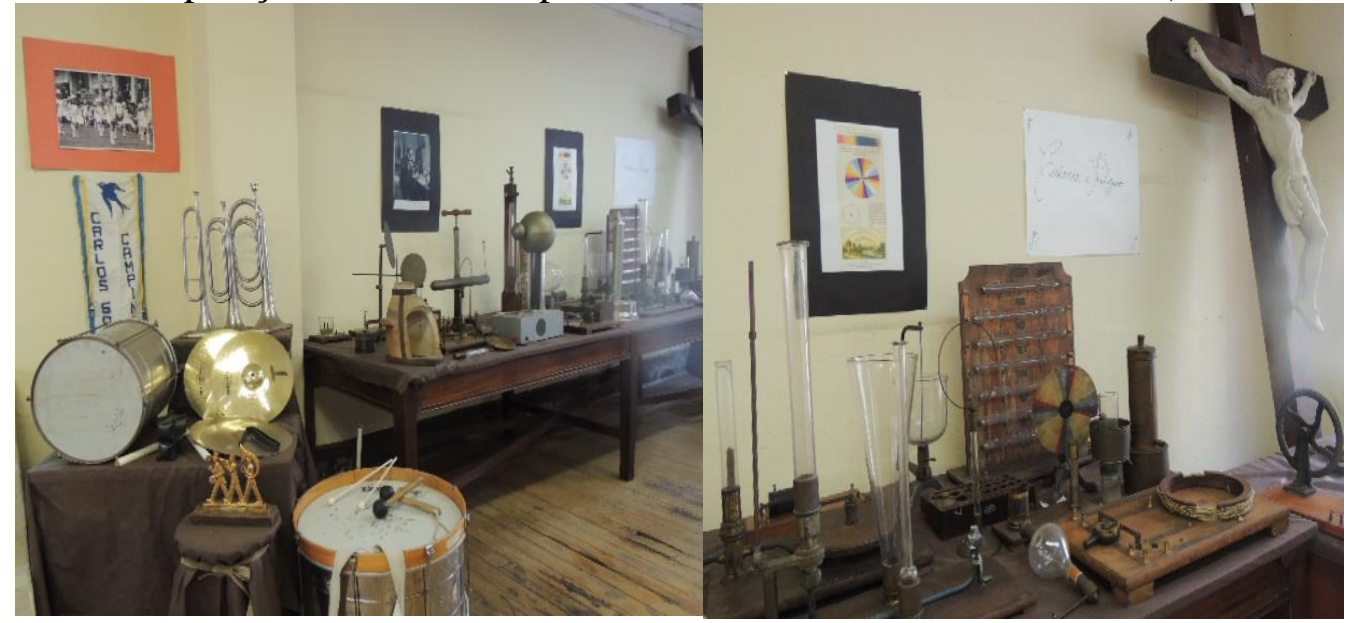

Fonte: Acervo do Grupo CIVILIS - FE-Unicamp

FIGURA 12 - Exposição em seu local permanente, antes da última reforma (outubro 2017)

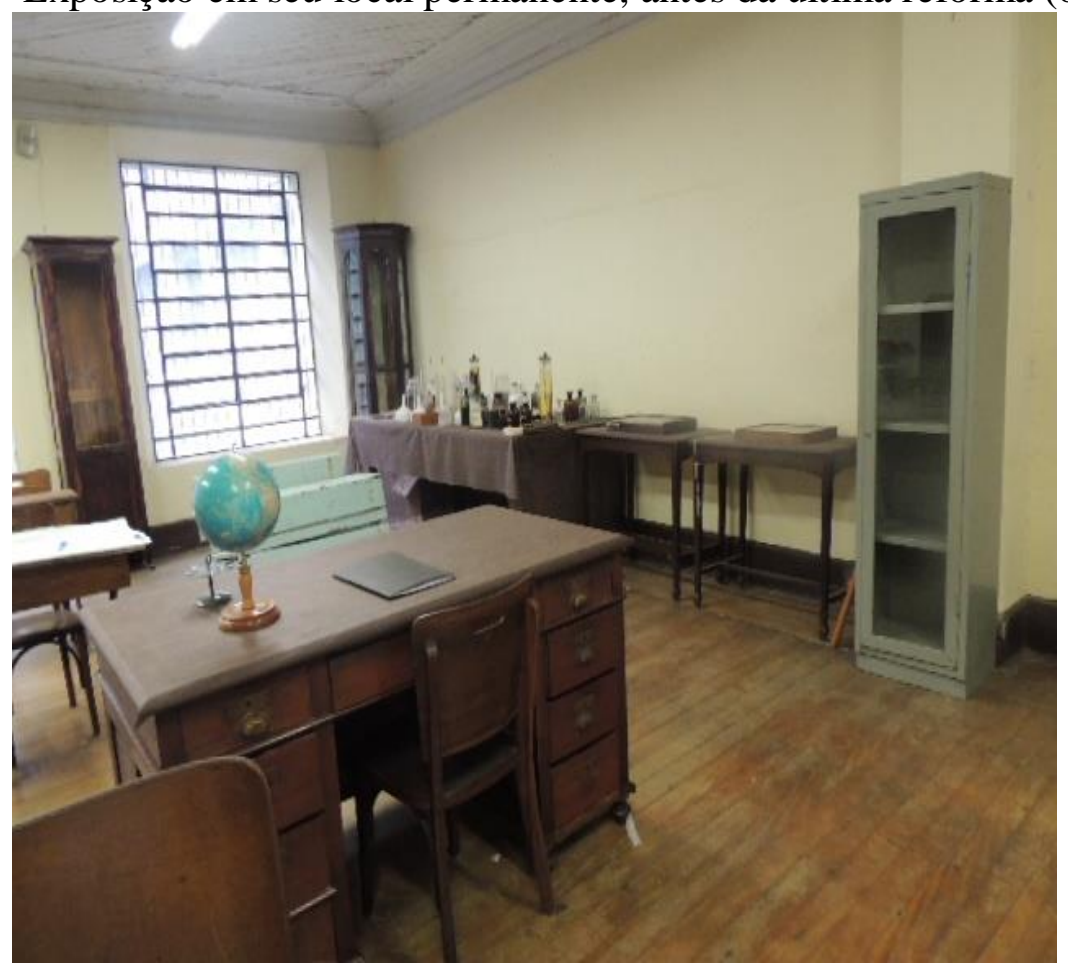

Fonte: Acervo do Grupo CIVILIS - FE-Unicamp 


\section{$(\mathrm{cc}) \mathbf{E Y}$}

FIGURA 13 - Equipe de apoio e a mudança da exposição para o porão

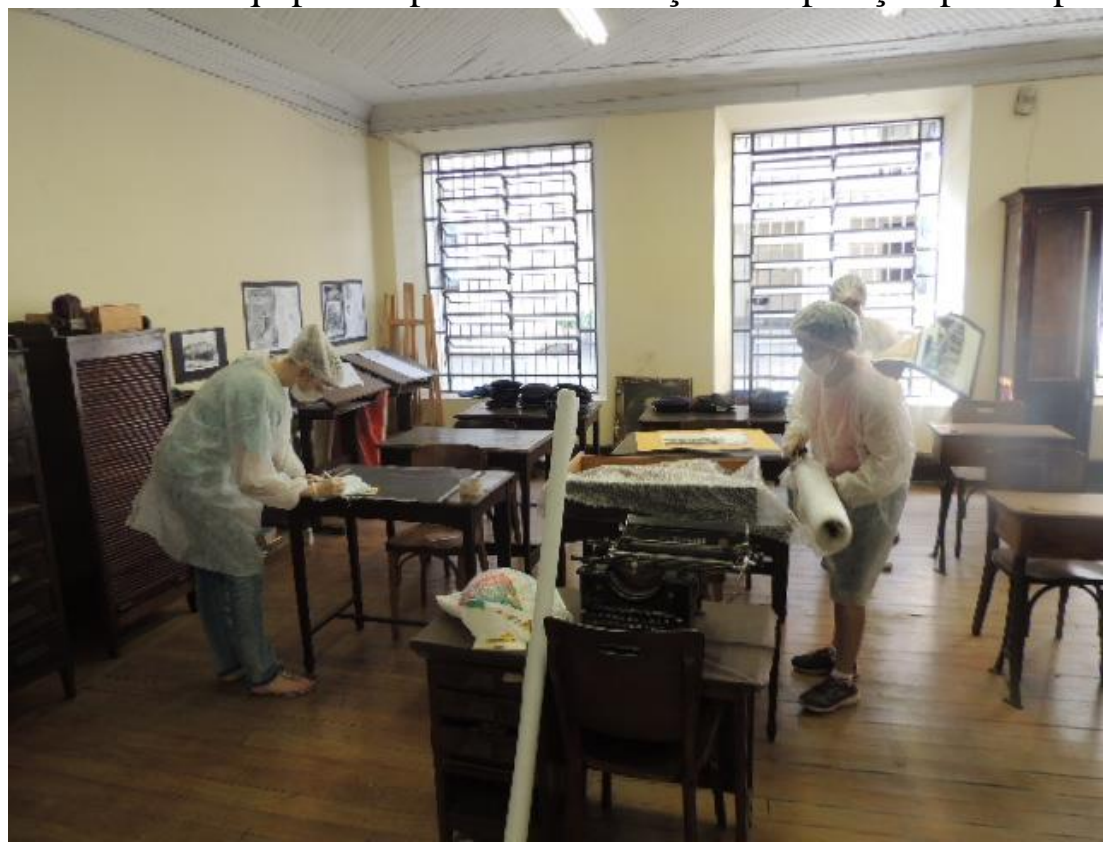

Fonte: Acervo Grupo CIVILIS - FE-Unicamp

FIGURA 14 - Equipe de apoio e a mudança da exposição para o porão

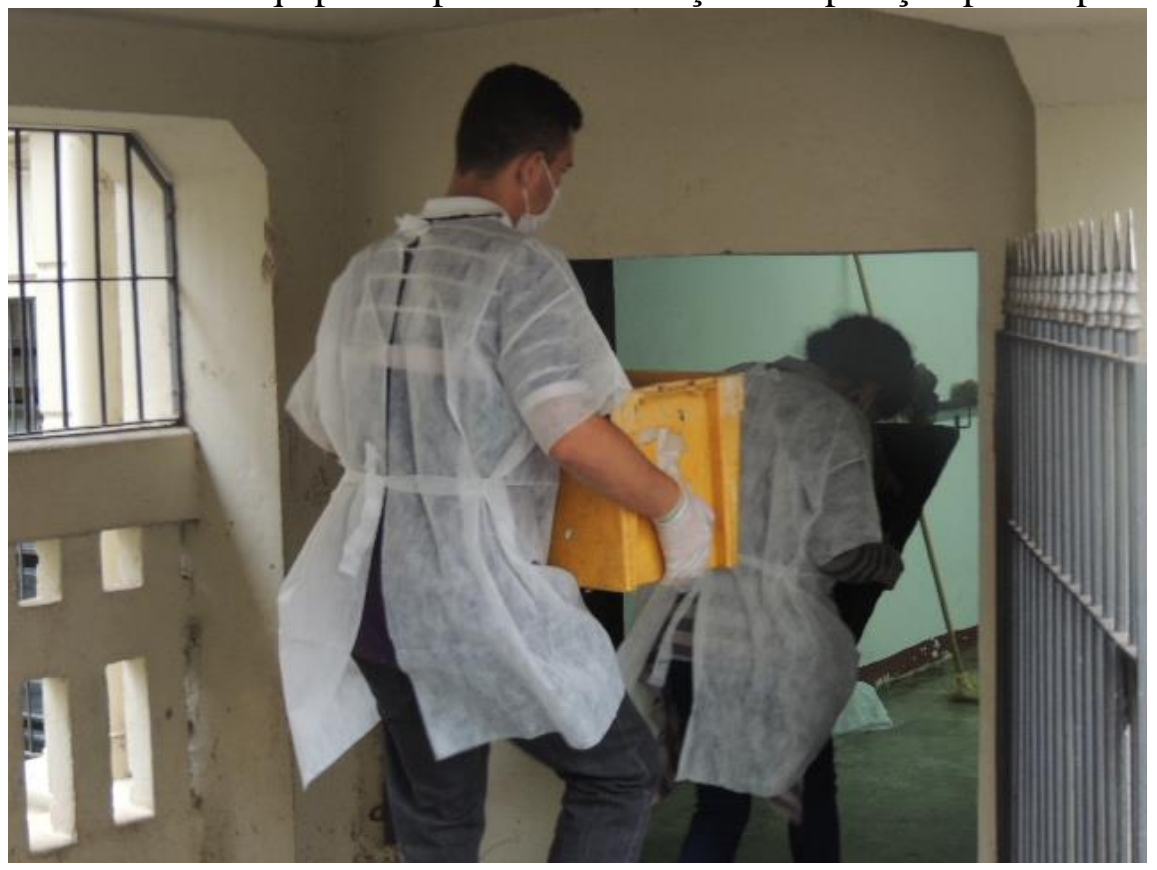

Fonte: Acervo Grupo CIVILIS - FE-Unicamp 


\section{$(\mathrm{cc}) \overline{E Y}$}

FIGURA 15 - Equipe de apoio e a mudança da exposição para o porão.

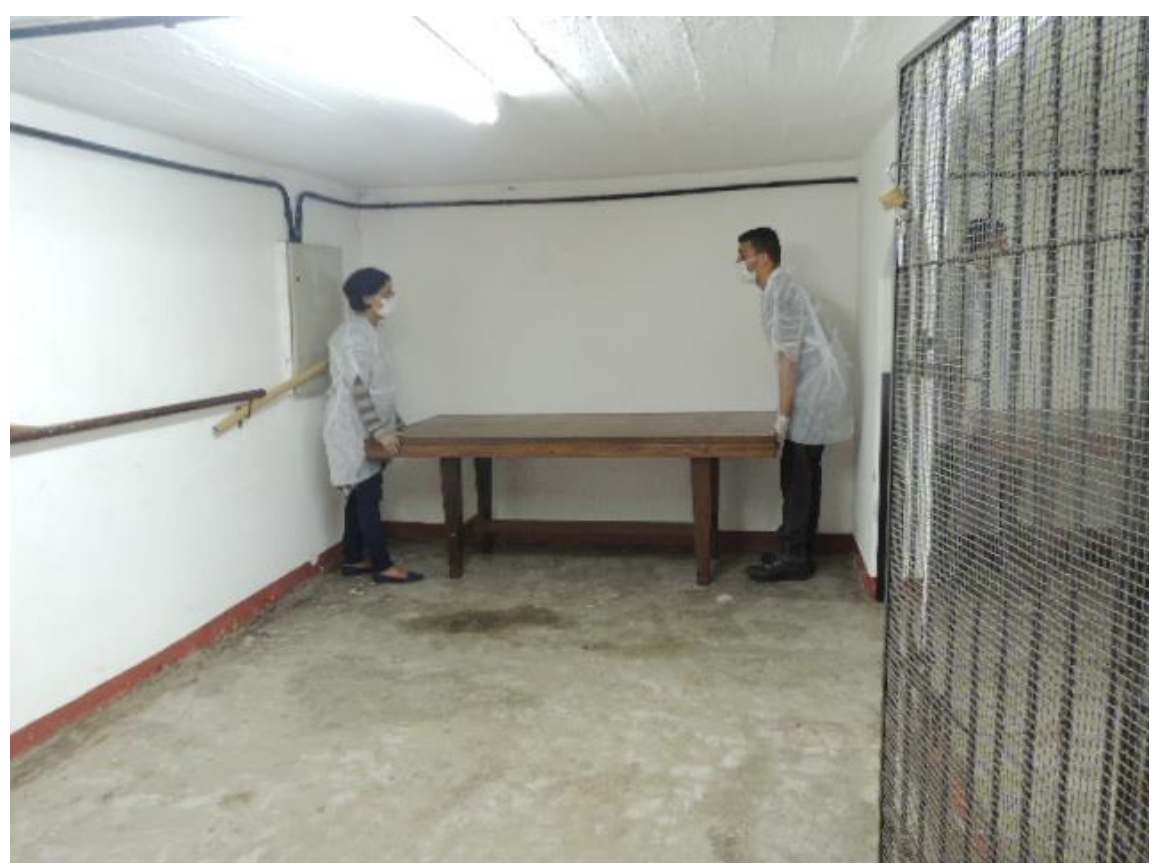

Fonte: Acervo Grupo CIVILIS - FE-Unicamp.

\section{FIGURA 16 - Exposição no porão}

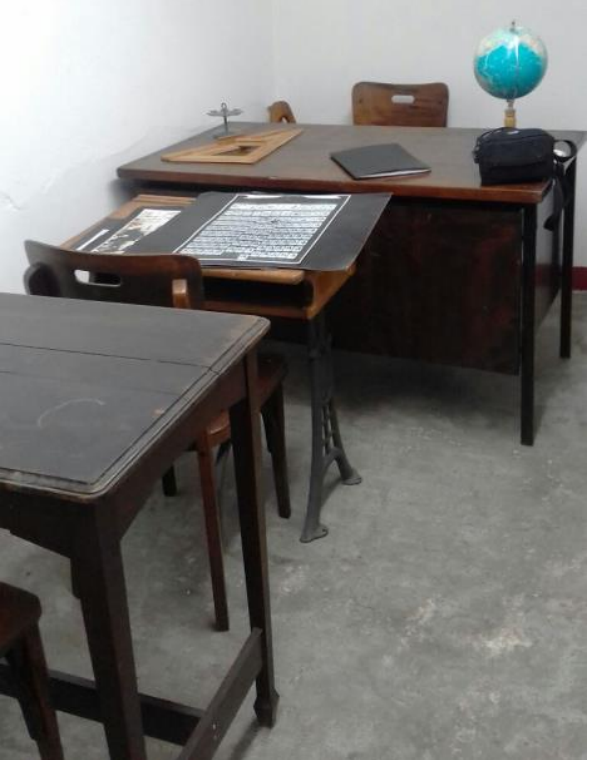

Fonte: Acervo Grupo CIVILIS - FE-Unicamp 


\section{(cc) EY}

FIGURA 17 - Exposição no porão

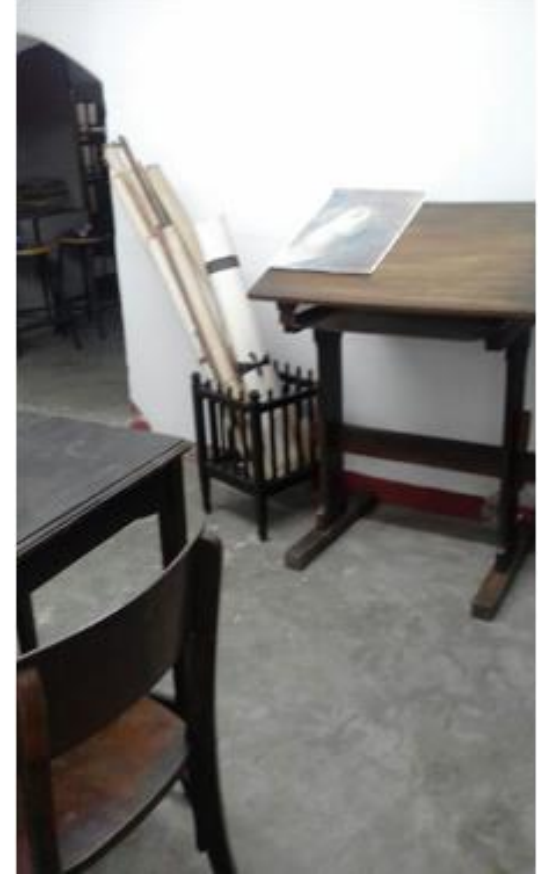

Fonte - Acervo Grupo CIVILIS - FE-Unicamp

FIGURA 18 - Exposição no porão.

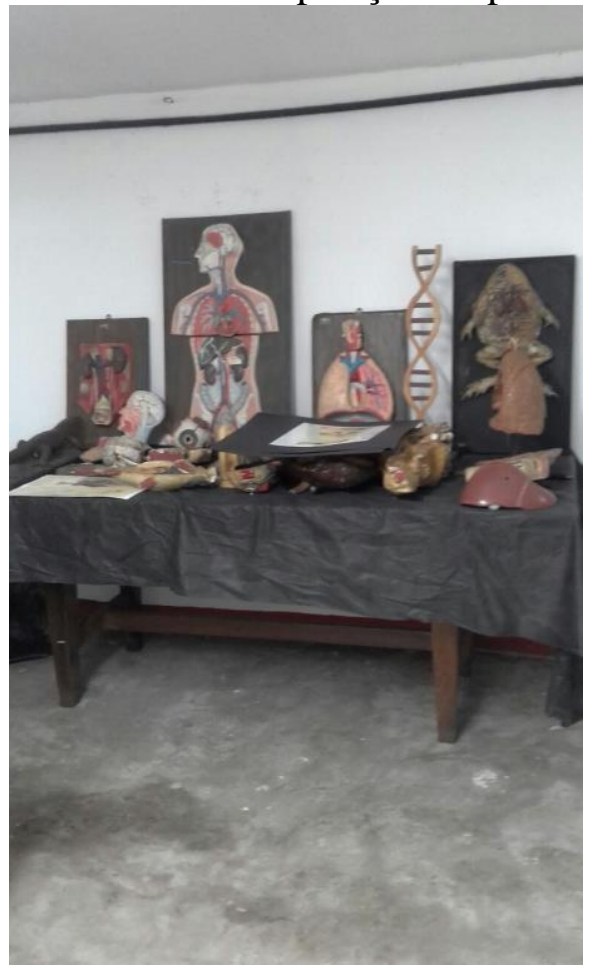

Fonte: Acervo Grupo CIVILIS - FE-Unicamp. 


\section{$(c)$ EY}

\section{Visita à Exposição "Siga Carlinhos e conheça a exposição sobre a Escola Estadual Carlos Gomes": interação com o público}

A proposta da visita à exposição do memorial baseou-se em um objetivo claro e relevante, que seria de ter sido fundamentada por meio da atividade sobre as maletas pedagógicas.

FIGURA 19 - Exposição sobre a E.E. Carlos Gomes - 22 de novembro de 2017

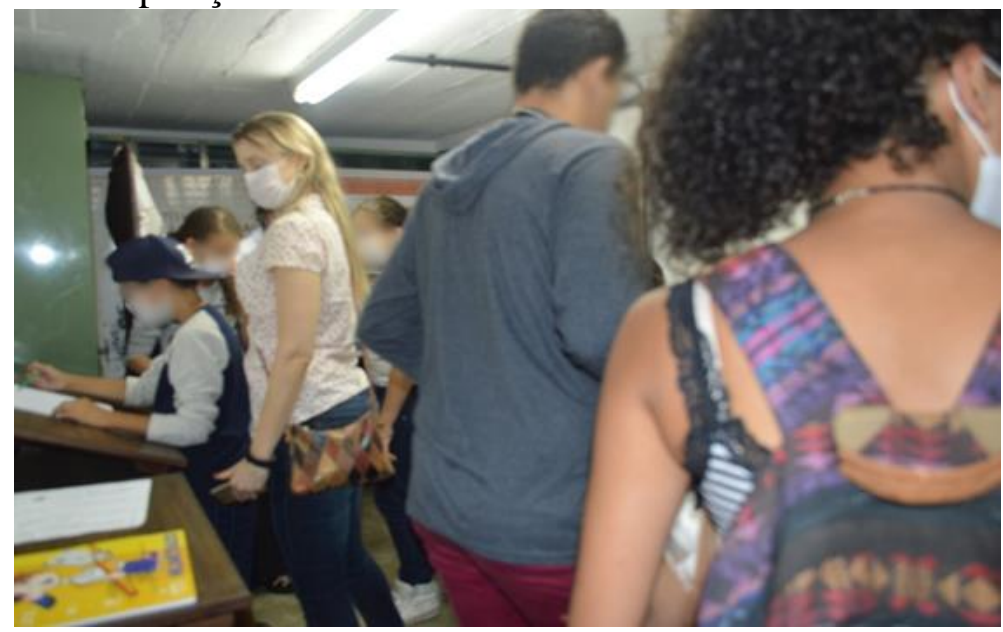

Fonte: Acervo Grupo CIVILIS - FE-Unicamp

Enfatiza-se que ao estruturar um projeto que envolvia a sensibilização quando da visita dos alunos ao museu houve a preocupação com as expectativas dos estudantes e com o fato de que tais expectativas fossem supridas ou negociadas.

FIGURA 20 - Exposição sobre a E. E. Carlos Gomes - 22 de novembro de 2017

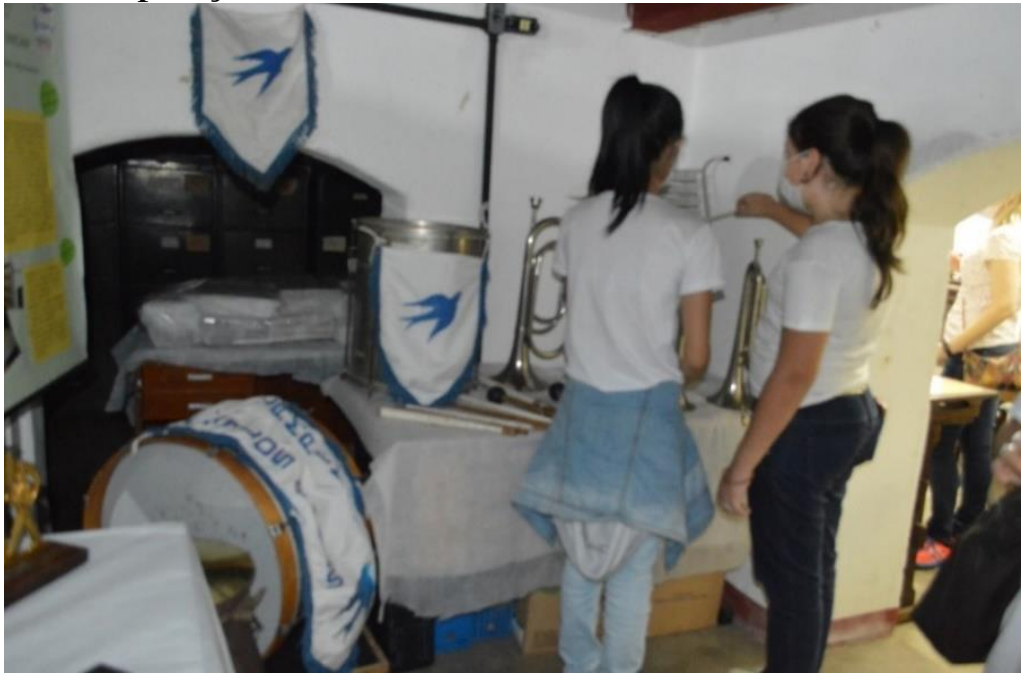

Fonte: Acervo Grupo CIVILIS - FE-Unicamp

Rev. Iberoam. Patrim. Histórico-Educativo, Campinas (SP), v. 6, p. 1-23, e020010, 2020. 


\section{(cc) EY}

A visita foi conduzida pelo "Carlinhos", o fantoche, "mascote oficial", o qual estimulou, tanto por meio de perguntas quanto pelo incentivo à observação dos alunos, ao interagirem com a exposição.

FIGURA 21 - Exposição sobre a E E. Carlos Gomes - 22 de novembro de 2017

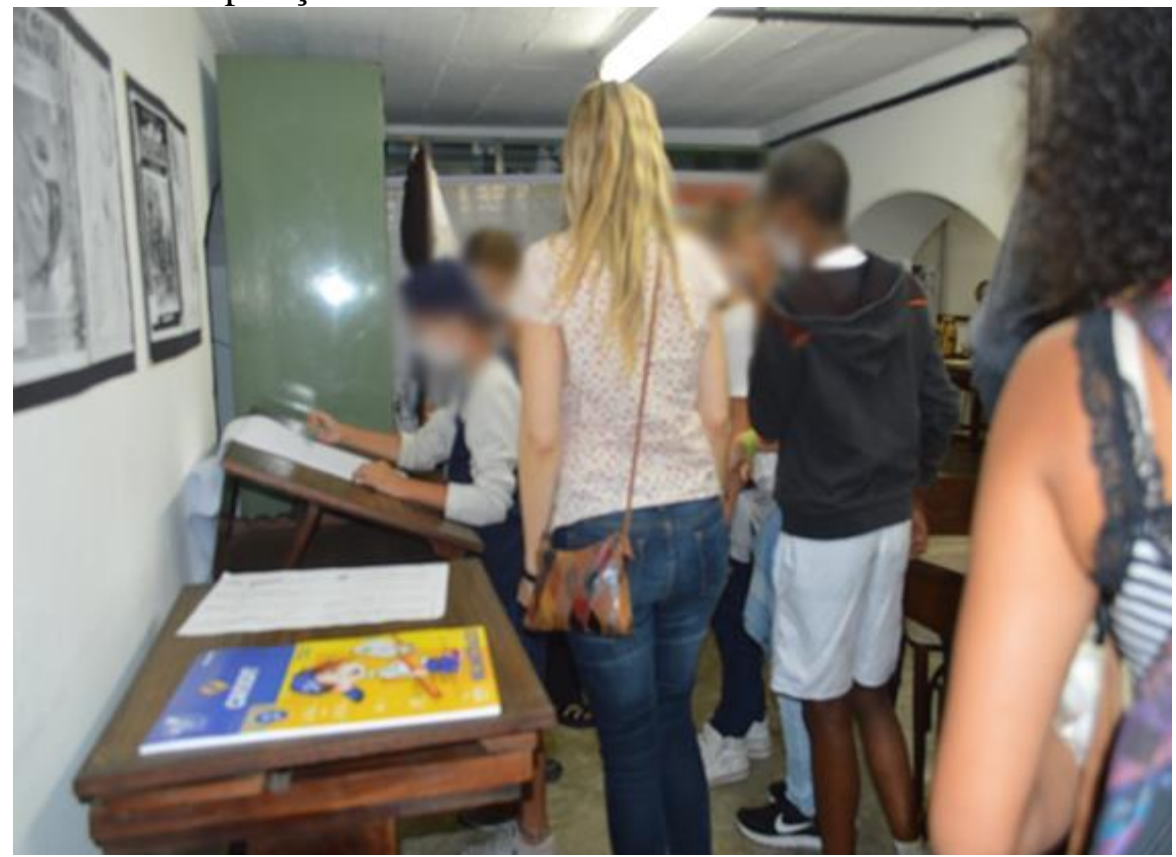

Fonte: Acervo Grupo CIVILIS - FE-Unicamp

Pôde-se constatar olhares de muita curiosidade durante a visita ao Museu.

FIGURA 22 - Exposição sobre a E.E. Carlos Gomes - 22 de novembro de 2017.

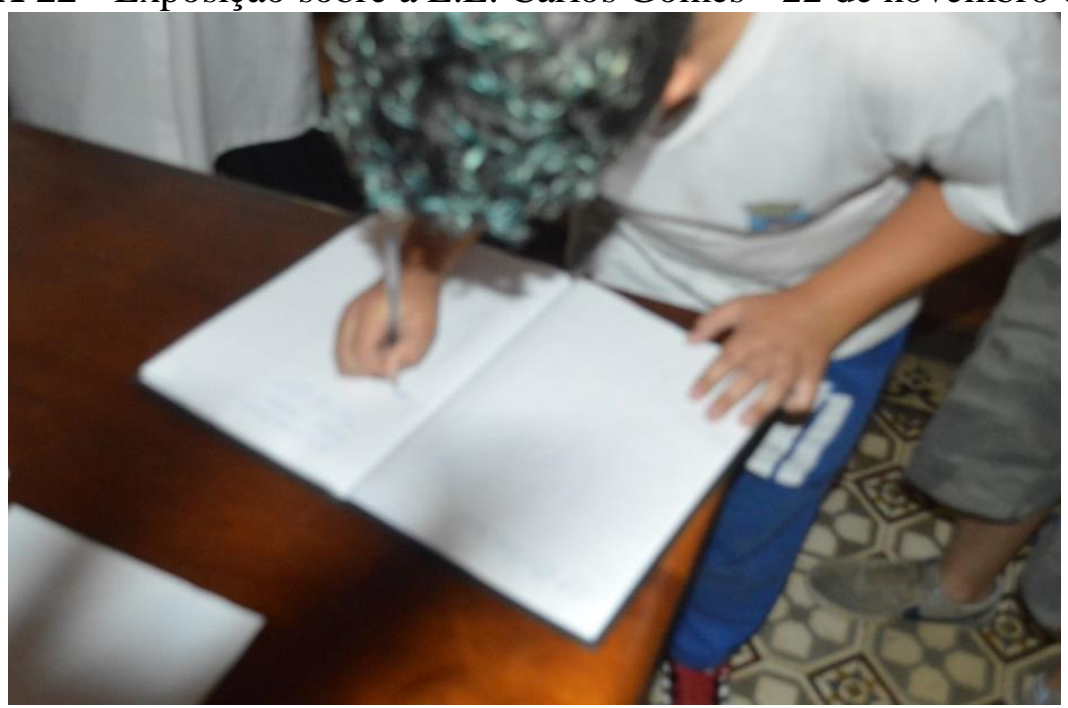

Fonte: Acervo Grupo CIVILIS-FE-Unicamp

Rev. Iberoam. Patrim. Histórico-Educativo, Campinas (SP), v. 6, p. 1-23, e020010, 2020. 


\section{$(c c)$ EY}

Cada turma comportou-se de uma maneira. A interação dos estudantes com a exposição foi nítida. O primeiro grupo (de 15 alunos) mexeu e tocou os instrumentos sem a necessidade da mediação dos professores que o acompanhava. Já ao segundo grupo foi importante indicar que podiam tocar os instrumentos para que, em seguida, iniciassem essa experimentação. Outros estudantes interessaram-se pelo globo terrestre e começaram a explorá-lo, ou seja, constatou-se a ocorrência de diferentes formas de interação.

A biblioteca histórica, cujo acervo se encontra em estantes, em outras naves (MENEZES, 2013) do porão, não foi inserida na exposição. Mas duas alunas descobriram a mesma e perguntaram o porquê de não poderem visitá-la. Por meio do questionamento das estudantes se vislumbra a curiosidade em conhecer o espaço escolar e os seus guardados, em atitude interativa.

Conforme discorreu ao longo da pesquisa, interação não apenas por meio de manusear objetos, mas também, elaborar associações e comentários, reagir com expressões verbais ou não, trocar sensações entre os pares e com os professores, em processo de reconhecimento e identificação do ambiente escolar.

Desta maneira, a partir da visita às exposições os alunos puderam se perceber como parte da coletividade da escola que estudam atualmente. E dependendo da força que isto foi recebido por cada aluno pode acarretar um "sentimento de pertencimento".

Muitos estudantes ficaram interessados na área da reserva técnica, pois viram que havia animais taxidermizados e uma cobra no formol. Naquele momento houve a possibilidade de se explicar o que é e a importância da Reserva Técnica em um museu.

Uma estudante, que disse adorar ler, encantou-se pelos livros de leitura que estavam expostos em cima das antigas carteiras escolares. Segundo relato da professora, a estudante perguntou, já na classe, se poderia ir ao museu toda semana para lê-los. Ou seja, conforme discorrido anteriormente o indivíduo pode envolver-se ativamente no desenvolvimento do conhecimento sem que envolva uma ação motora sobre os objetos.

A compreensão e a leitura da exposição escolar não se restringiu ao que foi dito pelo monitor ou ao que estava escrito nas plaquetas informativas. Essas informações mostram leitura do objeto estruturada pelos organizadores, mas foi importante que esta fosse significada pelos visitantes. Dessa forma, cada visitante pode ler os objetos ali expostos a partir de suas experiências próprias e nas relações "sensoriais" e "afetivas" que mantém com a exposição. Partiu-se da possibilidade de os visitantes interpretarem os objetos e se reconhecerem neles e nas situações

Rev. Iberoam. Patrim. Histórico-Educativo, Campinas (SP), v. 6, p. 1-23, e020010, 2020. 


\section{$(c)$ EY}

apresentadas. Também, se considerou que diferentes grupos de visitantes possuem expectativas distintas no que se relaciona à aprendizagem. O diálogo entre os objetos e o observador possivelmente possui formas variadas e se insere num "espectro" diferenciado de campos.

Finalmente, baseamo-nos, também, em uma abordagem de "perspectiva cultural" com o objetivo de estruturar as duas exposições. Segundo Hooper-Greenhill (1994), nesta perspectiva a realidade não se encontra intacta e é configurada por meio de um processo contínuo de negociação entre indivíduos que, por meio de suas experiências, constroem seus significados de forma ativa. Neste caso, a comunicação é vista como um processo de troca, de participação e de associação.

\section{Memorial laboratório de estudos e pesquisas escolares da Escola Estadual Carlos Gomes- Campinas-SP- 2019}

Como apresentado anteriormente, o Memorial da Escola Estadual “Carlos Gomes” é um espaço destinado para a discussão sobre história da educação escolar, em especial, daquela escola, por meio dos objetos museais, livros e documentos escolares que ali se encontram. Com a finalização da reforma, a exposição museal permanente retornou ao seu espaço de origem.

FIGURA 23 - Exposição de volta para seu local permanente - 2019

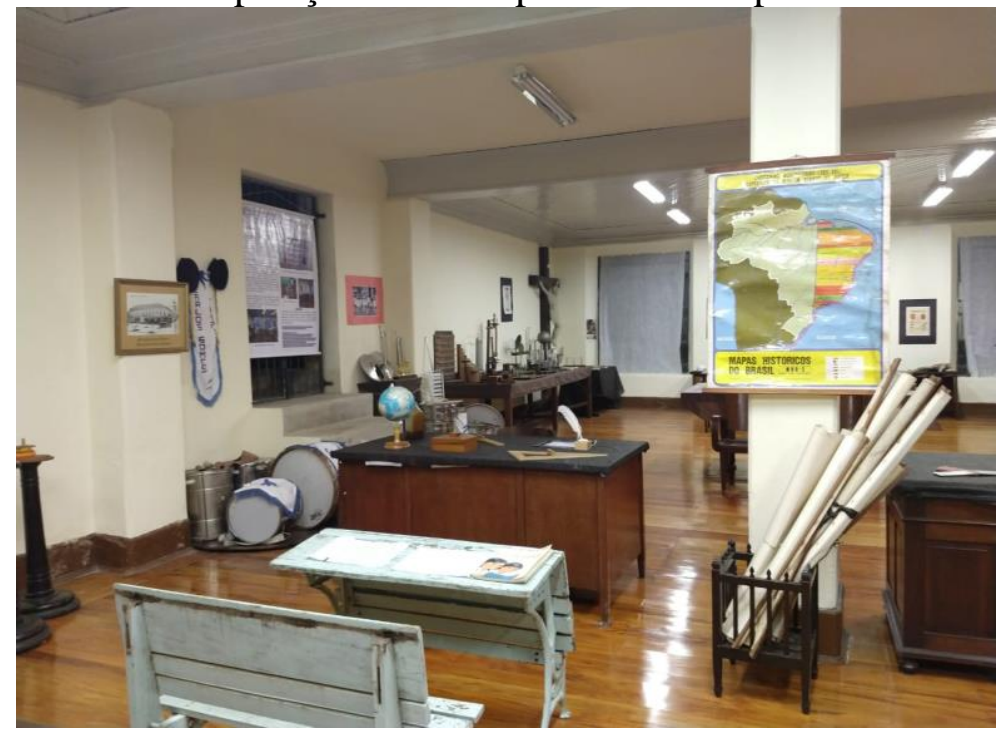

Fonte: Acervo Grupo CIVILIS - FE-Unicamp. 
FIGURA 24 - Exposição de volta para seu local permanente - 2019

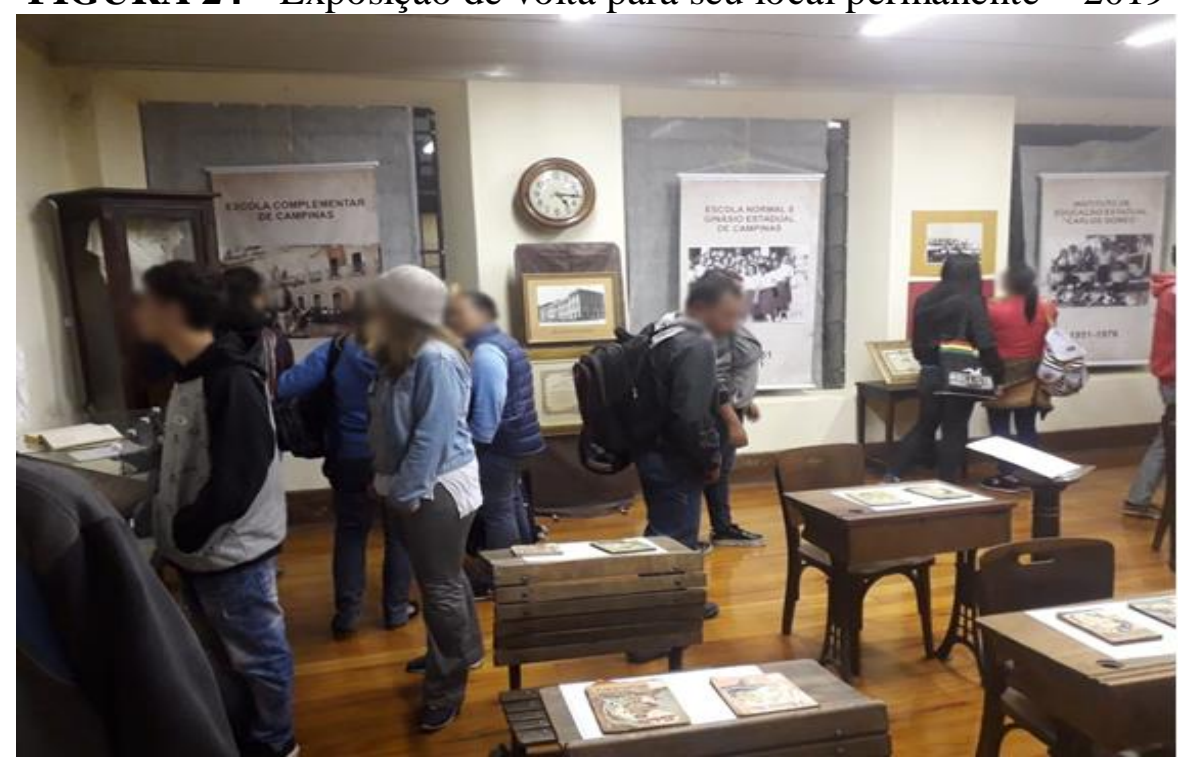

Fonte: Acervo Grupo CIVILIS - FE-Unicamp.

\section{CONSIDERAÇÕES FINAIS}

A discussão que se buscou proceder nesta pesquisa ganha a sua importância, sobretudo, quando articulada às preocupações de como os indivíduos conhecem e buscam, de distintas maneiras, projetar as "experiências" para os diferentes tipos de mostras, exposições e atividades educativas nos museus. E no caso dos Museus de Educação, a preocupação com a educação em museus é ressaltada, tanto no que se refere ao seu conteúdo patrimonial, quanto à política educativa que atravessa todas as esferas de atuação.

As exposições, ao se constituírem para além de simples conjunto de ilustrações e buscarem a comunicação com a audiência por intermédio de uma construção, na qual as palavras ilustrar, demonstrar e completar não são lidas de maneira mecânica, mas, interpretadas a partir de perspectivas direcionadas à compreensão, troca e cooperação, podem possibilitar a interação do sujeito com o objeto do conhecimento.

Baseando-se em Linares (2016), considera-se em um museu, o exercício de práticas, discursivas e sociais, que podem auxiliar tanto na reprodução como na modificação de outras práticas sociais. Assim, ressalta-se que uma exposição ao invés de um texto linear ou intertextual, mais aproxima-se de uma conjugação de linguagens museográficas, visuais, textuais, tácteis, corporais, entre outras, que estabelece uma relação dialética com o visitante.

Rev. Iberoam. Patrim. Histórico-Educativo, Campinas (SP), v. 6, p. 1-23, e020010, 2020. 


\section{(cc) EY}

Vivenciar a proposta "Sensibilização e visita ao memorial" sinalizou para o fato de as exposições, uma vez instaladas, estão em processo de desenho constante com a participação do público.

\section{REFERÊNCIAS}

ÁLVAREZ DOMÍNGUEZ, P. Nuevo concepto de los museos de educación. In: BERRIO, J. R. (Ed). El patrimônio histórico-educativo: su conservación y estudio. Madrid: Biblioteca Nueva, 2010, pp. 139-167.

ÁLVAREZ DOMÍNGUEZ, P. El museo de educación como centro de interpretación: revelar el sentido del patrimonio histórico educativo. In: VII JORNADAS CIENTIFICAS DE LA SEPHE Y V SIMPOSIO IBEROAMERICANO: Historia, Educación, Patrimonio Educativo, 7., 2016, País Vasco. Actas Espacios y patrimônio histórico-educativo. País Vasco, 2016. p. 1219-1234 ÁLVAREZ DOMÍNGUEZ, P. Viajes y maletas pedagógicas en la enseñanza y el aprendizaje de la Historia de la Escuela. IBER. Didáctica de las Ciencias Sociales y Experimentales, n. 73, p. 90-97, abril-mayo-junio, 2013.

BOSI, E. Memória e Sociedade: lembranças de velhos. São Paulo: Companhia das Letras, 1994.

FOX, M. Guilherme Augusto Araújo Fernandes. São Paulo: Brinque-Book, 2002.

HOOPER- GREENHILL, E. Los museos y sus visitants. Gijón: TREA,1998.

INSTITUTO DO PATRIMÔNIO HISTÓRICO ARTÍSTICO NACIONAL (IPHAN). Disponível em: http://portal.iphan.gov.br/. Acesso em: 18 set. 2017, 15 set. e 28 out. 2018.

INTERNATIONAL COUNCIL OF MUSEUMS (ICOM). Disponível em https://icom.museum/en/. Acesso em: 20 set. 2017, 16 set. e 28 out. 2018.

LINARES, M. C. Edutopías- Tecnologías en la escena educativa. In: VII JORNADAS CIENTIFICAS DE LA SEPHE Y V SIMPOSIO IBEROAMERICANO: Historia, Educación, Patrimonio Educativo, 7. 2016, País Vasco. Actas Espacios y patrimônio histórico-educativo. País Vasco, 2016. p. 1133-1144.

MENEZES, M. C. Patrimônio Histórico-Educativo: experiências de preservação em acervos escolares paulistas. In: CARVALHO, M. L. M. (Org.). Patrimônio, Currículos e Processos Formativos. São Paulo: CPS, Imprensa Oficial do Estado de São Paulo, 2013. p. 23-37.

POLLACK, M. Memória e Identidade Social. Estudos Históricos, Rio de Janeiro v. 5, n. 10, p. 200-2012, 1992. 
WAGENSBERG, J. Cosmocaixa. El museo total. Por conversación entre arquitectos y museólogos. Barcelona: Sacyr, 2006.

Recebido em: 09 de maio de 2020

Aceito em: 29 de junho de 2020 